\title{
APRESENTAÇÃO
}

\section{NANOTECNOLOGIAS: ELAS JÁ ESTÃO ENTRE NóS...}

\author{
Oswaldo Luiz Alves
}

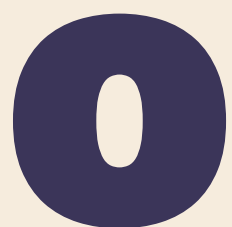

termo nanotecnologia tem sido usado para definir sistemas e processos que dão origem a bens ou serviços provenientes da matéria no nível nanométrico, isto é: na faixa de tamanho do bilionésimo do metro $\left(10^{-9} \mathrm{~m}\right)$, ou seja, o nanômetro (nm).

As nanotecnologias (no plural) são tecnologias para as quais estão sendo esperadas contribuiçôes significativas em termos de benefícios, cujas potencialidades podem vir a impactar positivamente a qualidade de vida da sociedade. Segundo a OCDE (Organização para a Cooperação e Desenvolvimento Econômico), do ponto de vista da inovação, as nanotecnologias podem ser descritas como uma "plataforma tecnológica".

Não restam dúvidas de que essas novas oportunidades acabarão tendo reflexos sobre o setor produtivo como um todo, gerando demandas de novos investimentos, de mão de obra especializada e, ao mesmo tempo, descortinando importantes questôes relacionadas à regulação.

Atualmente, há uma enorme quantidade de artigos científicos que expressam as possibilidades das nanotecnologias para a solução de vários problemas ligados à saúde, à energia, ao meio ambiente, às tecnologias da informação, ao tratamento de água, aos fármacos e medicamentos, aos cosméticos, entre outros. Além disso, é repertoriado um grande número de produtos (nanoprodutos), os quais têm as "nanotecnologias embarcadas" ou foram concebidos e produzidos usando seus conceitos.

Neste número temático de Ciência e Cultura, sobre as nanotecnologias, procuramos evidenciar alguns aspectos relacionados à Iniciativa Brasileira de Nanotecnologia, do Ministério da Ciência Tecnologia e Inovação (MCTI), no sentido de não só oferecer sionante cifra de 20 bilhões de dólares de faturamento anual.

ao leitor um panorama bastante geral dessas atividades no Brasil, mas também algumas políticas que norteiam essas iniciativas. Para tanto, Flávio Plentz e Adalberto Fazzio, ambos ligados ao MCTI, fazem considerações sobre o Programa Brasileiro de Nanotecnologia.

Neste conjunto, o artigo de Silvia Guterres e co-autoras, da Universidade Federal do Rio Grande do Sul (UFRGS), relaciona a nanotecnologia ao setor de higiene pessoal, perfumaria e, mais notadamente, cosméticos. A escolha vem do fato desse setor produtivo estar se tornando, em nível mundial, um dos grandes incorporadores das nanotecnologias. Tal atividade econômica, no Brasil, já ultrapassa a impres-

Como para toda a tecnologia nova, questôes de riscos e benefícios acabam gerando candentes discussões - no caso das nanotecnologias não seria diferente-, sobretudo porque o impacto das mesmas é esperado em importantes e estratégicos setores industriais. Governos, empresários, cientistas, legisladores e público em geral vêm discutindo essas questões, mormente aquelas ligadas ao risco potencial das nanotecnologias para o homem e o meio ambiente, que são englobadas pela sigla EHS, do inglês Environmental, Health and Safety. Considerando essa perspectiva, o artigo de Diego Stéfani Teodoro Martinez e Oswaldo Luiz Alves, ligados ao Laboratório de Química do Estado Sólido (LQES) e ao Laboratório de Síntese de Nanoestruturas \& Interação com Biossistemas (NanoBioss) do Instituto de Química da Universidade Estadual de Campinas (Unicamp), é importante por abordar o problema das interações envolvendo nanomateriais (nanopartículas) "engenheirados" - obtidos sinteticamente -, com biossistemas, propiciando a emergência de uma nova área do conhecimento, altamente multidisciplinar, que vem sendo conhecida como nanotoxicologia. Aqui, a intenção 
é mostrar a conexão desta emergente disciplina, com questões da própria regulação das nanotecnologias.

O desenvolvimento da ciência e tecnologia depende fundamentalmente de métodos, ferramentas e técnicas. As nanotecnologias têm entre suas techniques de choix as microscopias, aqui tomadas em senso largo. $\mathrm{O}$ artigo de Fernando Galembeck, atual diretor do Laboratório Nacional de Nanotecnologia, no Centro Nacional de Pesquisas em Energia e Materiais, trata desse assunto, enfoca as microscopias de sonda e, mais especificamente, a microscopia de força atômica (AFM) e toda uma gama de configuraçôes que a transformaram numa verdadeira "plataforma de microscopias". São apresentados vários exemplos onde essas ferramentas podem ser utilizadas com sucesso e que vão desde a avaliação de aspectos topográficos até a medida de potenciais elétricos de nanomateriais.

Finalmente, Mahendra Rai, professor da Universidade SGB Amravati, na Índia, tratará daquilo que vem sendo colocado como uma alternativa bastante interessante para a produção de alguns tipos de nanomateriais (nanopartículas), ou seja: a nanotecnologia verde (green nanotechnology). No caso em questão, para a produção dos nanomateriais de interesse e com funcionalidades definidas são usados extratos de plantas, biomassa, fungos, bactérias, entre outros. Os nanomateriais formados podem ser empregados como agentes antibacterianos, antimaláricos, no tratamento de água para o consumo humano etc, podendo vir a impactar políticas públicas de saúde em países menos desenvolvidos.

Muitos artigos reportados na literatura internacional colocam as nanotecnologias como verdadeira panaceia, ou seja: com capacidade para resolver todos os problemas. De nosso ponto de vista, vemos as nanotecnologias como uma grande plataforma de conhecimento científico-tecnológico, intrinsecamente inovadora e multidisciplinar, que aportará o desenvolvimento de novos produtos e soluções tecnológicas relevantes, mas que, no entanto, em muitos casos, terá que se mostrar mais eficiente, mais segura e apresentar uma relação custo/benefício favorável, quando comparadas com as tecnologias convencionais, estabelecidas e testadas anos a fio. Acreditamos, ainda, que ocorrerão situações nas quais teremos sistemas híbridos, constituídos por tecnologia convencional e nanotecnológica, atuando sinergisticamente.

Em vista dos pontos aqui levantados, não nos parece um exagero desmesurado fazermos coro àqueles que colocam as nanotecnologias como uma nova revolução científica e tecnológica.

Oswaldo Luiz Alves é professor titular e coordenador científico do Laboratório de Química do Estado Sólido (LQES), do Instituto de Quimica da Unicamp. Membro da Academia Brasileira de Ciências $(A B C)$. Email: oalves@iqm.unicamp.br.

\section{NOTA BIBLIOGRÁFICA}

1. Para conhecer aspectos básicos da nanotecnologia veja Alves, O.L., "Cartilha sobre nanotecnologia", Agência Brasileira de Desenvolvimento Industrial (ABDI). 2010. Disponível em PDF: . http://Iqes.iqm. unicamp.br/images/publicacoes_teses_livros_resumo_cartilha_ abdi.pdf (Acesso em maio de 2013).

\section{CONSIDERACÕES SOBRE o programa brasilemo DE NANOTEGNOLOGIA}

\author{
Flávio Plentz \\ Adalberto Fazzio
}

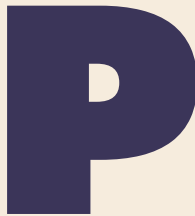

assaram-se cerca de 25 anos desde que a nanociência e nanotecnologia $(\mathrm{N} \& \mathrm{~N})$ começaram a integrar de forma mais consistente a agenda da comunidade científica e tecnológica. Hoje as N\&N permeiam essencialmente todos os setores da sociedade e geram opiniōes, por vezes, contraditórias. As reaçōes às nanotecnologias vão, atualmente, do mais contagiante otimismo, pelas possibilidades que oferecem para fazer frente a muitos dos grandes desafios da humanidade, como nas áreas da energia, saúde, agricultura e pecuária, processamento e armazenamento de informação, para citar apenas alguns, até o temor por possíveis impactos ambientais e efeitos adversos para a saúde humana e animal.

O lançamento da chamada "Iniciativa Americana de Nanotecnologia" é tomada por muitos como sendo um marco nas açōes governamentais articuladas, orgânicas, direcionadas especificamente para alavancar, incentivar, fomentar, coordenar e gerir as políticas e açôes em N\&N. Hoje, todos os países ditos desenvolvidos e um número grande e crescente de países emergentes e em desenvolvimento têm iniciativas e programas nacionais em $\mathrm{N} \& \mathrm{~N}$, inclusive o Brasil.

A revista Ciência \& Cultura já publicou alguns artigos abordando o tema da $N \& N(1 ; 2)$, o primeiro deles apontando para a necessidade de uma iniciativa brasileira de nanotecnologia que permitisse ao Brasil ser parte atuante no cenário mundial e o segundo apresentando algumas das fantásticas possibilidades que a nanotecnologia traz em termos de avanços, especialmente na área de saúde. Neste artigo o que pretendemos é apresentar o desenho do atual Programa Brasileiro de Nanotecnologia (PBN) que tem como bases: (i) a integração de diversos ministérios e agências; (ii) a melhoria da gestão e do acompanhamento dos programas, ações e iniciativas; (iii) a consolidação de uma infraestrutura moderna e, em especial, aberta e acessível, para a pesquisa, desenvolvimento e inovação (P,D\&I); (iv) prover meios, instrumentos, e ambiente regulatório adequado para que as nanotecnologias possam ser escalonadas, industrializadas e comercializadas e, por fim, mas com destaque para sua importância; (v) a formação e fixação de recursos humanos, sem os quais quaisquer esforços ou açōes ficam comprometidos.

No Ministério da Ciência, Tecnologia e Inovação (MCTI) a N\&N está sob a responsabilidade da Secretaria de Desenvolvimento Tecnológico e Inovação (Setec) através da Coordenação Geral de Micro e Nanotecnologias (CGNT). A CGNT conta com o suporte do Comitê Consultivo de Nanotecnologia (CCNANO) composto por pesquisadores, membros de entidades representativas do setor privado e pessoas ligadas a órgãos, agências, empresas e instituições do governo federal. 